\title{
Formulation and Evaluation of Lipstick with Betacyanin Pigment of Hylocereus polyrhizus (Red Dragon Fruit)
}

\author{
Theeoo Lwin', Cho Yi Myint ${ }^{2}$, Htet Htet Win ${ }^{3}$, Wah Wah 0o ${ }^{4}$ Khit Chit ${ }^{5}$ \\ ${ }^{1}$ Department of Pharmacology, University of Pharmacy-Mandalay, Mandalay, Myanmar \\ ${ }^{2}$ Department of Pharmaceutics, University of Pharmacy-Mandalay, Mandalay, Myanmar \\ ${ }^{3}$ Biotechnology Research Department, Kyaukse, Myanmar \\ ${ }^{4}$ Department of Food and Drug Administration, Mandalay, Myanmar \\ ${ }^{5}$ Department of Food and Drug Administration, Naypyidaw, Myanmar \\ Email: theeoolwin@mohs.edu.mm, theeoolwin007@gmail.com
}

How to cite this paper: Lwin, T., Myint, C.Y., Win, H.H., Oo, W.W. and Chit, K. (2020) Formulation and Evaluation of Lipstick with Betacyanin Pigment of Hylocereus polyrhizus (Red Dragon Fruit). Journal of Cosmetics, Dermatological Sciences and Applications, 10, 212-224.

https://doi.org/10.4236/jcdsa.2020.104022

Received: June 7, 2020

Accepted: December 28, 2020

Published: December 31, 2020

Copyright $\odot 2020$ by author(s) and Scientific Research Publishing Inc. This work is licensed under the Creative Commons Attribution International License (CC BY 4.0).

http://creativecommons.org/licenses/by/4.0/

\begin{abstract}
Lipstick is the most widely used cosmetic product. Although lipstick gives a lot of social, psychological and therapeutic benefits, it may harm the consumers. Because most lipsticks contained high lead level and long term use of high lead level lipstick may harm the consumers. Research findings have suggested that administration of various antioxidants can prevent or subdue various toxic effects of lead and generation of oxidative stress. Hylocereus polyrhizus (Red dragon fruit) is widely available in Myanmar and it contains powerful antioxidant amaranth colorant called betacyanin pigment. It can prevent the oxidative stress caused by low level of lead, thus suitable as natural colorant for lipstick. As a role of pharmacist, this research was intended to minimize the adverse effects of lipsticks by formulating natural lipstick with betacyanin pigment obtained from $H$. polyrhizus and other natural ingredients. Formulation of lipstick was carried out by heating and blending method with homogenizer at a speed of $12000 \mathrm{rpm}$. Then, $\mathrm{pH}$, melting point, surface abnormalities, aging stability, perfume stability and antioxidant activity were performed as quality evaluation. Skin irritation test, microbial analysis and lead content determination were carried out as safety evaluation. Formulated lipsticks with betacyanin pigment of $H$. polyrhizus have acceptable quality. The $\mathrm{IC}_{50}$ of standard ascorbic acid and formulated lipstick were $4.51 \mu \mathrm{g} / \mathrm{ml}$ and $22.23 \mu \mathrm{g} / \mathrm{ml}$ respectively. In quantitative analysis for microbiological control, formulated lipstick had no visible colony and in qualitative analysis, Staphylococcus aureus, E. coli and Pseudomonas aeruginosa were not detected in $0.5 \mathrm{~g}$ of formulated lipsticks. Moreover, lead content of formulated lipstick was only $2.9 \mathrm{ppm}$ that is within allowable limit and it had
\end{abstract}


negligible skin irritancy. Therefore, lipstick with betacyanin pigment of $H$. polyrhizus can utilize as Cosmeceutical.

\section{Keywords}

Lipstick, Lead, Betacyanin, H. polyrhizus, Quality, Safety, Red Dragon Fruit

\section{Introduction}

One of the most widely used cosmetic products is lipsticks. A lot of social, psychological and therapeutic benefits can be achieved from using lipstick. On the other hand, it may harm the consumers, because lipsticks might contain heavy metals especially lead. Lead is being used in lipstick with the purpose of retaining the color intensity of pigments [1]. While wearing lipstick, licking of lips or eating and drinking or kissing someone can cause ingestion of the lipstick's ingredients. Almost all women eat, drink, or lip while wearing the lipsticks and accordingly can cause swallows of 4.5 pounds of lipsticks per lifetime of a woman. Because of the accumulative nature in chronic exposure and neurotoxic nature, high level of lead in lipsticks should not be ignored.

In animal studies conducted in 2014, researchers found bioaccumulation lead $(\mathrm{Pb})$ in the blood of rats after 12 weeks of exposure to lipstick. That pointed out the exposure to lipstick can cause significant disposition of lead in the blood of rats. Research in many countries found that most lipstick contained high lead level and long term use of high lead level lipstick may harm the consumers [2].

Moreover, lipsticks with artificial dyes are often caused irritations such as dry lips, chapped lips and wrinkled lips to the lipstick users. In long term, the use of synthetic ingredients also raised safety concern due to adverse effects. Usually, the synthetic dyes used for color of the lipsticks are dangerous to humans for consumption. Coal tars used to prepare the synthetic dyes can cause drying of the lips, nausea, allergy and dermatitis. Worse, they can be carcinogenic and even fatal [3].

Research findings have suggested that administration of different antioxidants can prevent or subdue enormous toxic effects of lead and generation of oxidative stress [4]. The study on herbal lipstick formulation proved that lipsticks containing natural colorant were minimal side effects. In 2013, Swati and colleagues conducted a study on herbal lipstick formulation and proved that lipsticks containing natural color from Bixa orellana and Beta vulgaris were minimal and no evidence of side effect. Moreover, it had excellent properties like shining, spreading, and smoothness of lips [5]. Similarly, study of Sunil in Uttarakhand on formulation and evaluation of herbal lipstick showed that formulated herbal lipstick has better option to women with minimal side effects produced by the available synthetic ones [6]. Hylocereus polyrhizus (Red dragon fruit) is widely available in Myanmar and it contains powerful antioxidant amaranth colorant called betacyanin pigment. It can prevent the oxidative stress caused by low level 
of lead; thus betacyanin pigment is suitable as natural colorant for lipstick.

It is the role of pharmacists to formulate herbal lipstick as an alternative for the synthetic to minimize the side effects. Thus, the present work was designed to formulate natural lipstick as Cosmeceutical to minimize the adverse effects by using natural colorant betacyanin pigment obtained from $H$. polyrhizus and other natural ingredients.

\section{Objectives}

The primary objective of this study is to formulate and evaluate the lipstick with betacyanin pigment of $H$. polyrhizus. The detailed specific objectives of the study were:

1) To extract the betacyanin pigment from $H$. polyrhizus

2) To identify and quantify the betacyanin pigment

3) To formulate the lipstick with betacyanin pigment of $H$. polyrhizus

4) To carried out quality and safety evaluation of lipstick with betacyanin pigment

\section{Methodology}

\subsection{Study Design and Study Period}

It was laboratory base analytical study and the study period was from January 2016 to December 2016.

\subsection{Preliminary Procedures before Formulation of Lipsticks}

\subsubsection{Extraction of Betacyanin Pigment from $H$. polyrhizus}

Matured $H$. polyrhizus was collected from Patheingyi Township and authenticated. After authentication process, harvested fruits were cleaned and peeled by using Ceramic knife to avoid the interaction between the acidic compound present in the fruit and the steel or metal knife. Then fruit pulp was cut into small pieces and crushed by hands. The betacyanin pigment was extracted by cold maceration with 50\% ethanol for 3 days. Then, the extract was obtained by double filtering by muslin. The extract was concentrated by freeze drier and resultant concentrated solution was stored in refrigerator $\left(4^{\circ} \mathrm{C}\right)$ for future use.

\subsubsection{Identification and Quantification of Betacyanin Extract}

Betacyanin content of extract was determined by UV-Visible Spectrophotometer. Betacyanin content was measured in triplicate in de-ionized water. The extract was diluted by 100 -fold with deionized water to obtain the absorption value. After 20 minutes of equilibration, the quantification of betacyanin was carried out by applying the following equation [7].

$$
\mathrm{BC}=\frac{\mathrm{A} \times \mathrm{DF} \times \mathrm{MW} \times 1000}{\mathcal{E} \times \mathrm{L}}
$$

$\mathrm{BC}=$ Betacyanin concentration in $\mathrm{mg} / \mathrm{L}$

$\mathrm{A}=$ Absorption value at the absorption maximum $\left(\lambda_{\max }=536 \mathrm{~nm}\right)$

$\mathrm{DF}=$ Dilution factor 
MW = Molecular weight of betacyanin $(550 \mathrm{~g} / \mathrm{mol})$

$\varepsilon$ (Molar extinction coefficient of betacyanin $\left(60,000 \mathrm{~L} \cdot \mathrm{mol}^{-1} \cdot \mathrm{cm}^{-1}\right.$ in $\mathrm{H}_{2} \mathrm{O}$ )

$\mathrm{L}=$ Path length of the cuvette

\subsubsection{Pre-Formulation Study for Identification and Incompatibility}

Each ingredient used in formulation of lipstick was identified by scanning on FT-IR spectrophotometer and the resultant spectra were identified by comparing to the reference spectrum of each ingredient. The spectra obtained were saved for incompatibility study. Before main formulation of lipstick, incompatibility study was carried out by scanning the pre-formulated lipsticks on FT-IR spectrophotometer and incompatibility was checked by comparing the resultant spectrum with initial spectrum of each ingredient.

\subsection{Formulation of Lipsticks with Betacyanin Pigments}

Lipsticks were prepared by following formula derived from Cosmetic Chemistry (Red Lipstick). The detailed description of individual ingredient and proportion were described in Table 1.

Formulation of the lipsticks was carried out according to the Good Laboratory Practice (GLP) and steps involved were described in Figure 1. All the ingredients required were accurately weighed on a digital balance. Color extract containing betacyanin pigment was added to the $100 \mathrm{~mL}$ beaker and to which Olive oil was added. Then, the resultant mixture was heated on water bath to $70^{\circ} \mathrm{C}$ with little addition of Tween 20 as emulsifier. White beewax, Candellia wax, Cetearyl alcohol, Lanolin alcohol and Cocoa butter were placed in $100 \mathrm{~mL}$ beaker and heated to $70^{\circ} \mathrm{C}$ on temperature controlled hot plate. They were added subsequently according to their melting points. At $70^{\circ} \mathrm{C}$, all the ingredients were mixed while hot at $12,000 \mathrm{rpm}$ for next $10-15$ mins and then resultant lipstick was moulded. Then, the mould was rapidly cooled in freezer for 20 mins and the resultant lipsticks were transferred from mould to lipstick case.

Table 1. Description and proportion of ingredients used in lipstick with betacyanin pigment.

\begin{tabular}{|c|c|c|}
\hline \multirow{2}{*}{ Ingredients } & \multicolumn{2}{|c|}{ Detailed Description of the Ingredients } \\
\hline & Quantities (\%) & Comment \\
\hline White beewax & $15 \%$ & Hardness and Gloss \\
\hline Candellia wax & $10 \%$ & Hardness and Gloss \\
\hline Lanolin alcohol & $5 \%$ & Long lasting \\
\hline Cetearyl alcohol & $5 \%$ & Moisturizing \\
\hline Cocoa butter & $5 \%$ & Smoothing and Shining \\
\hline Olive oil & $50 \%-55 \%$ & Blending agent \\
\hline Extract (Betacyanin pigment) & $5 \%-10 \%$ & Natural color \\
\hline Fruity Essence & q.s & Flavoring agent \\
\hline Mica powder & q.s & Gloss and Opacity modifier \\
\hline
\end{tabular}




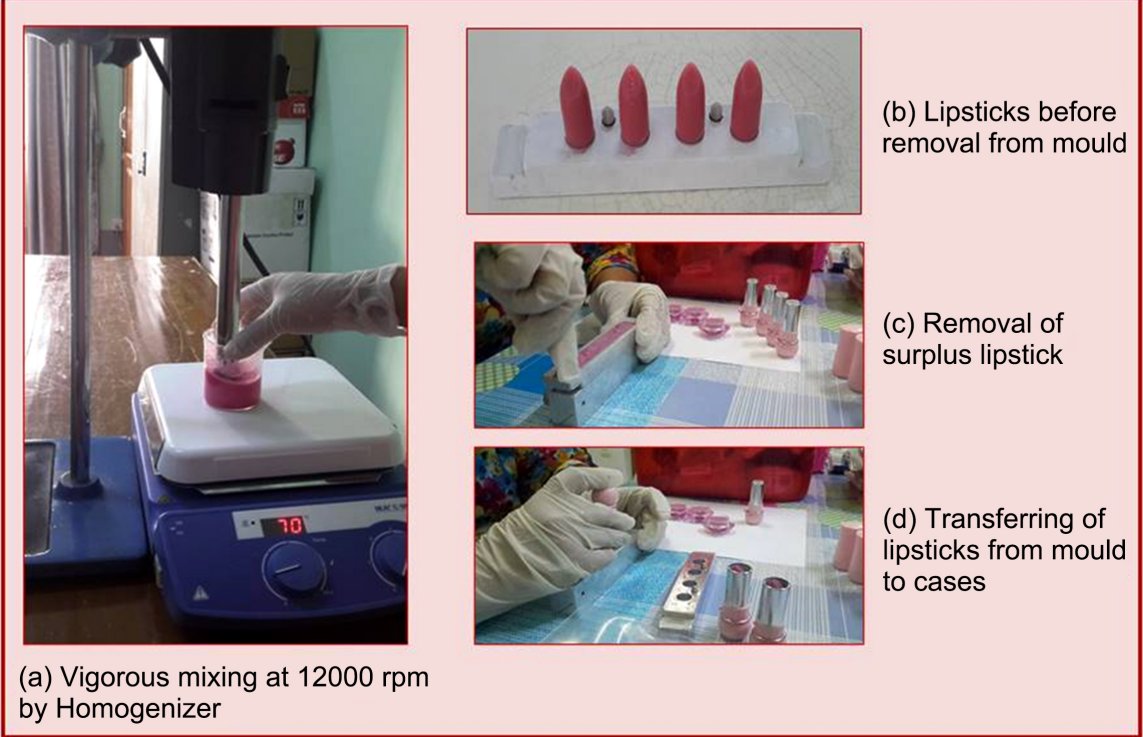

Figure 1. Formulation of lipstick with betacyanin pigment.

\subsection{Quality Evaluation of Lipstick with Betacyanin Pigment}

\subsubsection{General Evaluation}

\section{Melting Point}

Formulated lipsticks were completely melted on temperature controlled hotplate. Three capillary tubes were also placed in temperature control oven at $70^{\circ} \mathrm{C}$ for 10 mins. The melted lipsticks were poured into the capillary tube while hot and allowed to solidify for 10 mins. Then capillary tubes were placed into melting point measuring device. Melting point determination was done 3 times simultaneously and the melting point ratio was observed.

\section{Surface Abnormalities}

Formulated lipsticks were visually checked by an evaluator for surface defects such as crystal formation, contamination by mould and fungi etc.

\section{Aging Stability}

The formulated lipsticks were stored in temperature controlled oven at $40^{\circ} \mathrm{C}$ for 1 hour. The formulated lipsticks were evaluated for various parameters such as bleeding, crystallization of on surface and ease of application.

\section{$\mathrm{pH}$ Parameter}

The formulated lipsticks were placed in $25 \mathrm{ml}$ beaker and heated on temperature controlled hotplate at $70^{\circ} \mathrm{C}$. The probe of $\mathrm{pH}$ meter was placed into the beaker of melted formulated lipsticks and $\mathrm{pH}$ was measured during while hot.

\section{Perfume Stability}

The formulated lipsticks were stored at room temperature for 1 month and then evaluated by evaluator for the presence or absence of the fragrance.

\subsubsection{Evaluation of Antioxidant Activity (DPPH Assay)}

The antioxidant activity of extract and formulated lipstick were determined by the DPPH free radical scavenging assay. Briefly, the reaction mixture containing 
$10 \mu \mathrm{L}$ of test sample $(2,4,6,8,10 \mu \mathrm{g} / \mathrm{mL})$ and $90 \mu \mathrm{L}$ of DPPH $(60 \mu \mathrm{mol})$ dissolved in ethanol, was taken in a 96-well micro-titer plate and kept standing at $37^{\circ} \mathrm{C}$ for 30 mins. The absorbance was measured at $517 \mathrm{~nm}$ by using 96 well microplate-reader and spectrophotometer (Spectrostar Nano, BMG Labtech Microplate Reader). Ascorbic acid was used as standard. Percent radical scavenging activity (\%RSA) was calculated by using the following formula;

$$
\% \text { RSA }=1-\left(\frac{\mathrm{OD}_{\text {Test }}}{\mathrm{OD}_{\text {Control }}}\right) \times 100 \quad[8]
$$

$\%$ RSA $=$ Percentage Radical Scavenging Activity

$\mathrm{OD}_{\text {Test }}=$ Absorbance of test compound

$\mathrm{OD}_{\text {Control }}=$ Absorbance of DPPH alone

The $\mathrm{IC}_{50}$ of Standard ascorbic acid, extract and lipstick with betacyanin pigment were calculated from \%RSA by GraphPad Prism 5 software [log (inhibitor) Vs. normalized response-variable slope].

\subsection{Safety Evaluation of Lipstick with Betacyanin Pigment}

\subsubsection{Mouse Ear Irritancy Test}

Three months old healthy 10 females ddY strain albino mice (mean body weight $=25$ - $28 \mathrm{~g}$ ) were selected. After acclimatization 1 week period, albino mice were divided into 2 groups and mice were performed in test procedure and each group consisted of 5 numbers of mice for experimentation with each test samples. For the test groups of mice, each mouse was lightly anaesthetized with chloroform and approximately $10 \mathrm{mg}$ of lipstick samples were applied to the dorsal portion of left ears of them. Other side of ears serves as an untreated control. Daily application is carried out up to 4 successive days and checked assessment of irritation. Assessment was carried out immediately before applications were made during the first 4 days of experiment. On the fifth day, assessment was carried out 24 hour after the last (fourth) application of test samples. The daily difference between negative control ear and treated ears for each animal are summed to give an overall total for all the mice in an experiment. A correction is made for any difference between control and treated ears initially. The total, divided by 5 , yields a mean for each test material for the experimental period [9].

\subsubsection{Microbial Analysis}

Microbial analysis was carried out to ensure the microbial safety of formulated lipsticks for customers to use and to confirm hygienic and high quality handling. The microbial analysis of the samples was determined by spread plate method by modifying method of Hitchins and colleagues. Briefly, $1 \mathrm{~g}$ of the sample was diluted with the sterilized normal saline solution to get 1:10 dilution and the diluted samples were mixed thoroughly. $0.5 \mathrm{~mL}$ of each of the diluted samples were pipetted onto the surface of a solidified agar medium and spread evenly with a sterilized glass spreader rod. After spreading, the plates were incubated at 
$37^{\circ} \mathrm{C}$ for $48 \mathrm{hrs}$. For total combined yeast and mold count, the plates were incubated at $25^{\circ} \mathrm{C}$ and observed daily for 7 days. After incubation period, the colonies grown on the plate were counted and the number of bacteria in the original sample was calculated by multiplying with the dilution factor. The results were reported as cfu/g (mL) sample [10]. The following different Media were used for the determination of presence or absence of different pathogenic microbes in the samples.

1) Nutrient Agar for total aerobic microbial count

2) Potato Dextrose Agar (PDA) for total combined yeast and mold count

3) Mannitol Salt Agar (MS) for Staphylococcus aureus

4) Cetrimide Agar for Pseudomonas aeruginosa

5) Eosin Methylene Blue Agar (EMB) for Escherichia col.

\subsubsection{Lead Content Determination}

One gram of lipstick was accurately weighed on a digital balance. The lipstick was digested by triacidic mixture (70:7:23) of Nitric acid, Sulphuric acid and Perchloric acid on electronically temperature controlled hotplate until white fume was obtained. The digestion was carried out at low temperature at first followed by increase in temperature. The digest was cool and quantitative amount of de-ionized water was added and was filtered into $10 \mathrm{~mL}$ volumetric flask. After cooling, the final volume was adjusted volumetrically with de-ionized water [1]. Sample solutions were freshly prepared by digestion method. The resultant solutions were injected into Flame AAS and lead contents were determined at optimized condition by proposed method. All the measurements were triplicate. The results of sample were expressed as part per million (ppm).

\section{Results and Discussion}

\subsection{Preliminary Procedure before Formulation of Lipstick}

UV-assay showed that betacyanin concentration of the extract is $643 \mathrm{mg} / \mathrm{L}$. Duration is the critical factor that determines the betacyanin concentration and antioxidant activity. To obtain the extract with high antioxidant activity at least 48 hours maceration time is crucial. The long the extraction time, the more the betacynin concentration. The results obtained from the present study on betacyanin concentration were similar to the study of Naderi in Malysia [11]. Hydroalcholic solution especially $50 \%$ ethanol had highest betacyanin concentration. Therefore, the $50 \%$ ethanol was solvent of choice for extraction of betacyanin. Spectra obtained from FT-IR showed that all the ingredients used for formulation were authentic materials. All the spectra of raw materials were compared with formulated lipstick's spectrum. Characteristic bands of raw materials did not change (Figure 2). Pre-formulation incompatibility study confirmed that all the ingredients used for formulation of lipstick were compatible with color extract containing betacyanin because there were no significant spectrum changes after formulation. 


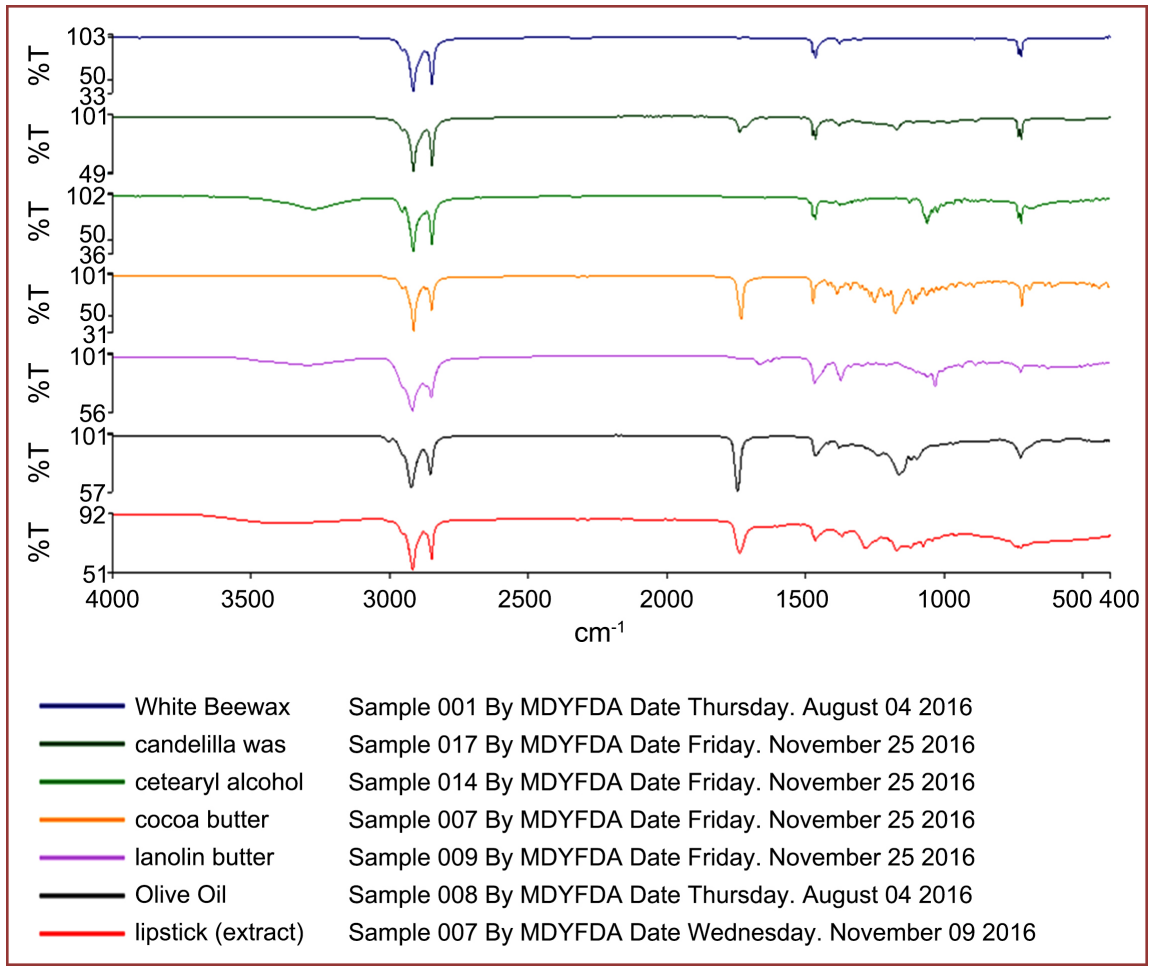

Figure 2. Comparison of spectrum of raw materials and lipstick with betacyanin pigment.

\subsection{Formulation of Lipstick with Betacyanin Pigment}

Formulated lipstick with betacyanin pigment had eligible appearance and attractive color but low tintorial power. Hardness was neither soft nor hard. The formula used in this study was the simplest formula for lipstick formulation but it can give desired properties. The present study showed that temperature is the main influence factor in lipstick formulation. Lipid medium and liquid medium must have the same temperature at the time of mixing; otherwise, creaming problem was occurred during formulation process. Mixing and emulsification is important point in formulation. The lipsticks formulated from the betacyanin pigment were described in Figure 3.

\subsection{Quality Evaluation of Lipstick with Betacyanin Pigment}

\subsubsection{General Evaluation}

Data obtained from the general evaluation of formulated lipsticks revealed that the formulated lipsticks had the acceptable quality (Table 2). The formulated lipsticks had appropriate organoleptic characteristics (color, odor and appearance). It was observed that there was no sweating, bleeding, streaking and blooming after one week of observation, when the products were store in room temperature for one month and oven temperature $\left(40^{\circ} \mathrm{C}\right)$ for an hour. The melting point of formulated lipstick was less than $60^{\circ} \mathrm{C}$. The $\mathrm{pH}$ value of formulated lipstick was very near to neutral $\mathrm{pH} 7$ and no surface abnormalities, no visible sign of mould and fungi. Aging stability test also showed that formulated lipstick had suitable physical quality requirement. 


\subsubsection{Evaluation of Antioxidant Activity}

The $50 \%$ inhibitory concentration for free radical $\left(\mathrm{IC}_{50}\right)$ of Standard ascorbic acid was $4.51 \mu \mathrm{g} / \mathrm{ml}$. The $\mathrm{IC}_{50}$ value of ethanolic extract of Red dragon fruit, lipstick with betacyanin pigment were 10.28 and $22.23 \mu \mathrm{g} / \mathrm{ml}$ respectively. \% RSA on DPPH radical at five serial concentrations of Standard ascorbic acid, Red dragon fruit extract, lipstick with betacyanin pigment were described in Figure 4.

Table 2. Parameters for general evaluation of lipstick with betacyanin pigment.

\begin{tabular}{|c|c|c|}
\hline & \multicolumn{2}{|c|}{ General Evaluation of Lipstick } \\
\hline & Parameter & Results \\
\hline 1 & Melting point & $55.3^{\circ} \mathrm{C} \pm 1.2^{\circ} \mathrm{C}$ \\
\hline 2 & $\mathrm{pH}$ & $6.5 \pm 0.2$ \\
\hline 3 & Perfume stability & Marked odor 1 month later \\
\hline 4 & Surface abnormality & $\begin{array}{l}\text { No surface defect, no crystal formation, } \\
\text { no mould \& fungi, no bleeding }\end{array}$ \\
\hline 5 & Aging stability & $\begin{array}{c}\text { Ease of application, no crystal formation, } \\
\text { no bleeding and marked odor }\end{array}$ \\
\hline
\end{tabular}

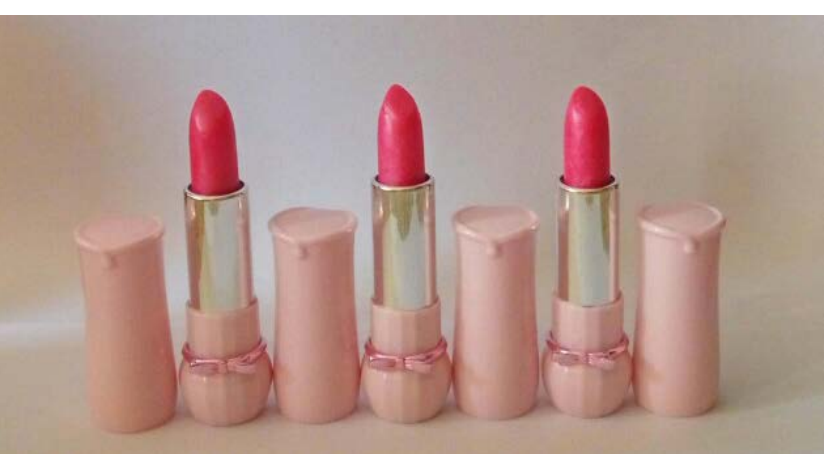

Figure 3. Lipsticks with betacyanin pigments of $H$. polyrhizus.

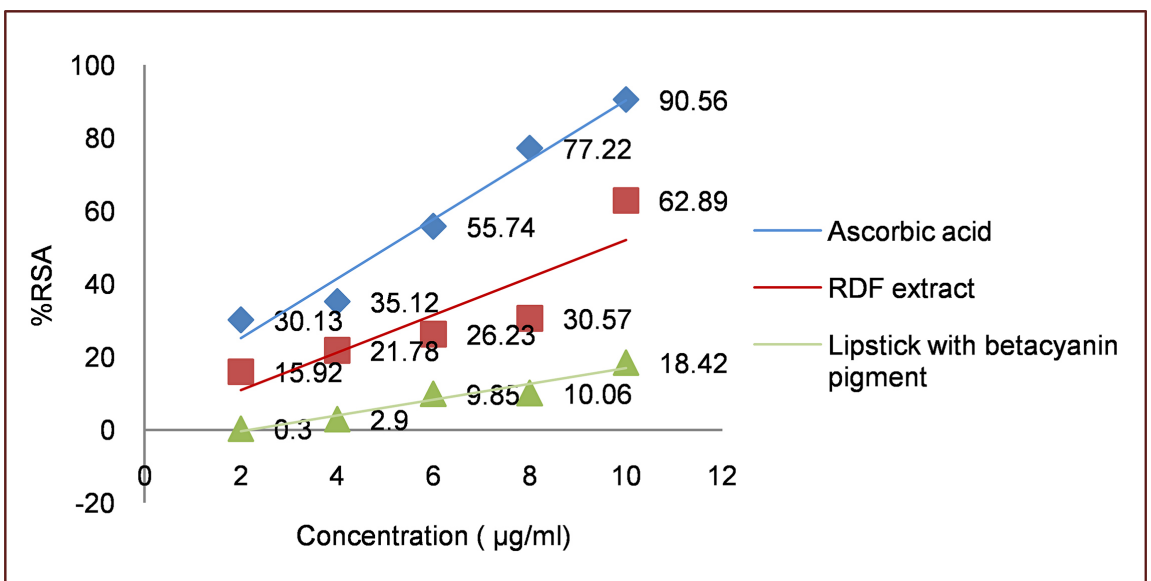

Figure 4. \% RSA on DPPH radical at five serial concentrations of Standard ascorbic acid, Red dragon fruit extract and Lipstick with betacyanin pigment. 
Azwanida and his colleagues reported that 50\% inhibitory concentration $\left(\mathrm{IC}_{50}\right)$ of formulated lipstick with betalanin pigments extracted from RDF was $54.29 \pm 1.9 \mu \mathrm{g} / \mathrm{ml}$ and $\mathrm{IC}_{50}$ value of the formulated lipstick (without pigment added) was $76.31 \pm 0.43 \mu \mathrm{g} / \mathrm{ml}$ while the $\mathrm{IC}_{50}$ value for the reference ascorbic acid was $14.56 \pm 0.24 \mu \mathrm{g} / \mathrm{ml}[3]$.

The present study showed that $\mathrm{IC}_{50}$ values of red dragon fruit extract was approximately 2 times greater than those of standard ascorbic acid. Accordingly, the antioxidant activity of Red dragon fruit was satisfactorily high. High antioxidant activity of extract was mainly due to the presence of betacyanin compound. The $\mathrm{IC}_{50}$ value of lipstick was greater 2.3 times greater than those of RDF may be due to the dilution of extract with other ingredients and exposure to relative high temperature $70^{\circ} \mathrm{C}$ during formulation process.

\subsection{Safety Evaluation of Lipstick with Betacyanin Pigment}

\subsubsection{Mouse Ear Irritancy Test}

The responses obtained from the Mouse ear irritancy test also less than 9 (Table 3 ). The statistical analyses of variance were performed by ANOVA with Microsoft Office Excel 2010 for Windows and P value less than 0.05 considered as statistically significant. The formulated lipsticks were not statistically significant from control ears in mouse ear irritancy test. Therefore it can be concluded that the formulated lipsticks have negligible skin irritancy.

In many studies on formulation of herbal lipstick, skin irritation test was carried out on 10 human volunteers. With new cosmetic ingredients, laboratory animal studies should invariably be carried out before they are tested on human skin; even with well-known raw materials, it is prudent to screen new formulations similarly. Therefore, mouse ear irritancy test was carried out in present study instead of human volunteers.

\subsubsection{Microbial Analysis}

Formulated lipstick was products of category 2 and microbial analysis of lipstick sample proved that these lipsticks was microbiological suitable for cosmetics use. In quantitative analysis for microbiological control, lipsticks with betacyanin

Table 3. Observation score for mouse ear irritancy test.

\begin{tabular}{|c|c|c|c|c|c|c|c|c|c|}
\hline \multirow{2}{*}{ No. } & \multirow{2}{*}{$\begin{array}{l}\text { ddY strain albino } \\
\text { female mice }\end{array}$} & \multicolumn{6}{|c|}{$\begin{array}{c}\text { Application: Once per day } \\
\text { (Dose }=0.01 \mathrm{~g} \text { of test sample) }\end{array}$} & \multirow{2}{*}{ Category } & \multirow{2}{*}{$\mathrm{p}$-value } \\
\hline & & Day 1 & Day 2 & Day 3 & Day 4 & Day 5 & $\begin{array}{c}\text { Final } \\
\text { Response }\end{array}$ & & \\
\hline 1 & $\begin{array}{l}\text { Negative } \\
\text { Control Ear }\end{array}$ & 1 & 1 & 1 & 1 & 2 & - & \multirow{3}{*}{$\begin{array}{l}\text { Probably not } \\
\text { perceptibly } \\
\text { irritant to } \\
\text { human skin }\end{array}$} & \multirow{3}{*}{$>0.05$} \\
\hline 2 & $\begin{array}{l}\text { Group A Mice } \\
\text { (Lipstick Base) }\end{array}$ & 2 & 2 & 2 & 2 & 4 & 1.2 & & \\
\hline 3 & $\begin{array}{c}\text { Group B Mice } \\
\text { (Formulated Lipstick) }\end{array}$ & 2 & 2 & 2 & 2 & 2 & 0.8 & & \\
\hline
\end{tabular}

Interpretation for Final response; $<9=$ not perceptibly irritant, $10-15=$ slightly irritant, $>15=$ sufficiently irritant. 
pigment had no visible colony. Yeast and mould were not detected in $0.5 \mathrm{~g}$ of both formulated lipstick sample. Moreover in qualitative analysis, Staphylococcus aureus, E. coli and Pseudomonas aeruginosa were not detected in $0.5 \mathrm{~g}$ of formulated lipstick.

Microbial analysis of lipstick with color extract of Red dragon fruit was satisfactory. No bacterial, mould and yeast, fungi were detected. Potentially pathogenic microorganisms such as Staphylococcus aureus, Pseudomonas aeruginosa and $E$. coli were not detected. This may be due to antibacterial activity of ethanolic extract of Red dragon fruit and preservative do not require for lipstick with color extract of Red dragon fruit within the study period. This pointed out the antimicrobial activity of RDF extract. This finding was consistent with the research finding of Azwandia in Malaysia that the pigments of Red dragon fruit possess potent antimicrobial activity.

\subsubsection{Lead Content Determination}

The present study found formulated lipstick that using betacyanin pigment as color ingredient had very low level of lead. The mean lead content in lipstick with betacyanin pigment was only $2.88 \pm 0.09 \mathrm{ppm}$. In contrast to the market sample lipsticks, mean leads content of natural color lipsticks was very lower than mean lead content of Counterfeit, Fair Price, Regular Price, Less Expensive and Expensive lipstick groups (Figure 5). Very low level of lead was detected. Detected amount of lead in these formulated lipsticks with natural color are lower than the specified limit of FDA $(20 \mathrm{ppm})$ and limit of Health Canada (10 ppm) [12] [13]. Form the result of this study showed that natural color compound can reduce the lead content of lipstick.

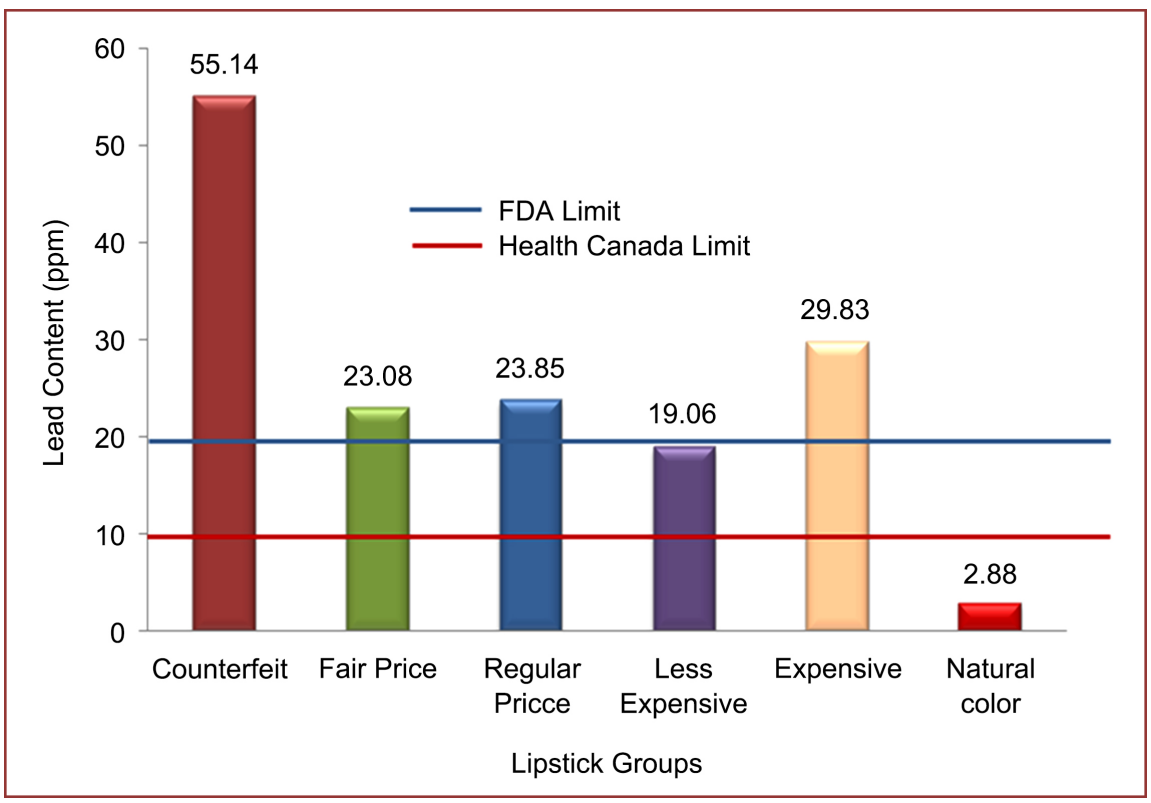

Figure 5. Comparison of lead contents of market sample lipsticks and formulated lipstick [14]. 


\section{Conclusion}

This study researched on reducing the lead content of lipstick by using betacyanin pigment obtained from $H$. polyrhizus instead of synthetic dye. Formulated natural color lipsticks have acceptable quality, safety and very low level of lead. Antioxidant activity analysis showed that formulated lipstick was satisfactory. In this study, formulated lipstick with betacyanin pigment enriched with natural oil; moreover, it can reduce the oxidative stress of lip, thereby preventing dry lips and slowing the aging of lips. Therefore, it can be used as Cosmeceutical and using the natural color can reduce the lead content of lipstick.

\section{Acknowledgements}

I would like to record my deep gratitude to Dr. Sein Hla Htwe, Dr. Khin Phyu Phyu, Dr. Aye Win Oo, Dr. Mar Mar Swe, Dr. Khaing Saw Thant, Daw Theingi Maung, U Sai Phone Myint Kyaw for their support in my research work.

\section{Conflicts of Interest}

The authors declare no conflicts of interest regarding the publication of this paper.

\section{References}

[1] Sah, R.C. (2012) Poison Cosmetics: The Problem of Lead in Lipstick in Nepal. Nepal, Centre for Public Health and Environmental Development (CEPHED), 2-6.

[2] Hashemi-Moghaddam, H., Shiravi, A., Shadab-Shamsabad, F. and Torabi, M. (2014) Disposition of Lead (Pb) in Blood of Rats Following Oral Exposure to Lipstick. E3S Web of Conferences, 1, 12003. https://doi.org/10.1051/e3sconf/20130112003

[3] Azwanida, N.N., Normasarah, N., and Afandi, A. (2014) Utilization and Evaluation of Betalanin Pigment from Red Dragon Fruit (Hylocereus polyrhizus) as a Natural Colorant for Lipstick. Teknologi Journal, 69, 139-142. https://doi.org/10.11113/jt.v69.3326

[4] Nurul, S.R. and Asmah, R. (2014) Variability in Nutritional Composition and Phytochemical Properties of Red Pitaya (Hylocereus polyrhizus) from Malaysia and Australia. International Food Research Journal, 21, 1689-1697.

[5] Swati, D., Manish, S., Sonia, S., Pawankumar, M.K., Khiraj, P. and Ganesh, N. (2013) Formulation and Evaluation of Natural Lipsticks Prepared from Bixa orellana seeds and Beta vulgaris Root Extract and Their Comparative Study. International Journal of Pharmacy and Pharmaceutical Sciences, 5, 68-70.

[6] Sunil, R., Shekhar, T.C. and Ashutosh, B. (2013) Formulation and Evaluation of a Herbal Lipstick: A New Approach. International Journal of Pharmaceutical Erudition, 3, 26-30.

[7] Cai, Y. and Corke, H. (1999) Amaranthus Betacyanin Pigments Applied in Model Food Systems. Journal of Food Science, 64, 869-873. https://doi.org/10.1111/j.1365-2621.1999.tb15930.x

[8] Lee, S., Son, D., Ryu, J., Lee, Y.S., Jung, S.H., Lee, S.Y. and Shin, K.H. (2004) Antioxidant Activities of Acanthopananax senticosus Stems and their Lignan Compo- 
nents. Archives of Pharmacal Research, 27, 106-110.

https://doi.org/10.1007/BF02980055

[9] Uttley, M. and Abbê, J.V. (1973) Primary Irritation of the Skin: Mouse Ear Test and Human Patch Test Procedures. Journal of Society of Cosmetic Chemists of Great Britain, 24, 217-227.

[10] Hitchins, A.D., Tran, T.T. and McCarron, J.E. Bacteriological Analytical Manual: Microbiological Methods for Cosmetics.

https://www.fda.gov/food/laboratory-methods-food/bam-chapter-23-methods-cos $\underline{\text { metics }}$

[11] Naderi, N., Ghazali, H.M., Hussin, A.S.M., Amid, M. and Abd-Manap, A.S. (2012) Characterization and Quantification of Dragon Fruit (Hylocereus polyrhizus) Betacyanin Pigments Extracted by Two Procedure. Journal of Tropical Agricultural Sciences, 35, 33-40.

[12] Health Canada (2012) Guidance on Heavy Metal Impurities in Cosmetics. Retrieved December 18, 2015. 2015/02/Pretty-Scary.

https://www.safecosmetics.org/wp-content/uploads/

[13] Ouremi, O.I. and Ayodele, O.E. (2014) Lipsticks and Nail Polishes: Potential Sources of Heavy Metal in Human Body. International Journal of Pharmaceutical Research and Allied Sciences, 3, 45-51.

[14] Lwin, T., Oo, K.M., Wai, K.Z., Lwin, C.C. and Chit, K. (2018) Determination of Lead Content in Red Colored Lipsticks from Mandalay Market by Flame Atomic Absorption Spectrophotometer. Myanmar Health Sciences Research Journal, 30, 167-173. http://www.myanmarhsrj.com https://doi.org/10.34299/mhsrj.30.03.0045 